\section{THE PHYSICAL HISTORY OF THE} VICTORIA FALLS.

W HEN Dr. Livingstone discovered the Victoria Falls in 1855 , he sought to explain their origin by calling in volcanic agency, and stated that they were "simply caused by a crack made in the hard basaltic rock from the right to the left bank of the Zambezi, and then prolonged from the left bank away through 30 or 40 miles of hills." All subsequent travellers support the same idea; but in his article Mr. Molyneux, in the Geographical Journal, claims that, as at Niagara, the combination of cañon, gorge, chasm, and falls is due to erosion and the constant reducing action of the Zambezi River (Fig. 1).

In explaining his theory, the author first refers to present-day conditions of the river, and divides it into three portions; the coastal, stretching 360 miles up as far as the Kebrabasa Range-a portion of the mountain axis of South Africathrough which it runs in a gorge 35 to 40 miles in length. The middle reach is 600 miles long, in low-lying country, and is divided from the upper regions of the river by the high Victoria Falls, I000 miles from the coast.

The geology of the country around the falls is then sketched briefly. During what was probably the Tertiary period, South Central Africa was subject to vigorous volcanic action, the concrete forms of which can now be seen in the denuded and exposed lava-flows of the Limpopo and Zambezi valleys. In the vicinity of the falls, the Batoka country, the basalt is interbedded with the soft forest sandstones, but the Zambezi River, in draining the ancient lake regions of Central Africa, has eaten into the overlying sediments until it has reached the hard and almost level igneous sheet in which the falls occur. This sheet extends from the end of the cañon, 40 miles east of the falls, to beyond the Gonye Falls, 120 miles northwest.

On reaching the top of this sheet, the erosive action of the river was checked; but conditions were more favourable in the middle regions of the river, which had no protective covering, and where the rocks are unresisting sandstones and Coalmeasures. A difference of level between the two regions came into existence-defined by the eastern edge or fringe of the basalt sheet.

It may be understood that the eastern edge would be thin, and the backward erosion of the Zambezi from its middle reaches would quickly break into it. But as the thickness of the basalt increased as the river receded westwards, the cutting action became slower, until the rate of deepening of the middle reach and Kebrabasa gorge far outstripped the slower process of forming the Grand Cañon of the Victoria Falls. The difference between the river bed where running on the basalt sheet

1 Abstiact of a paper by Mr. A. J. C. Molyneux in the Geographical Journal for January.

NO. I 852 , vOL. 7 I] and the altitude of the central reach became more exaggerated as time passed. Including the height of the falls ( 400 feet), this difference is now about 1000 feet.

Of the process by which the river cut back this Grand Cañon and shaped the falls as they are seen to-day, the

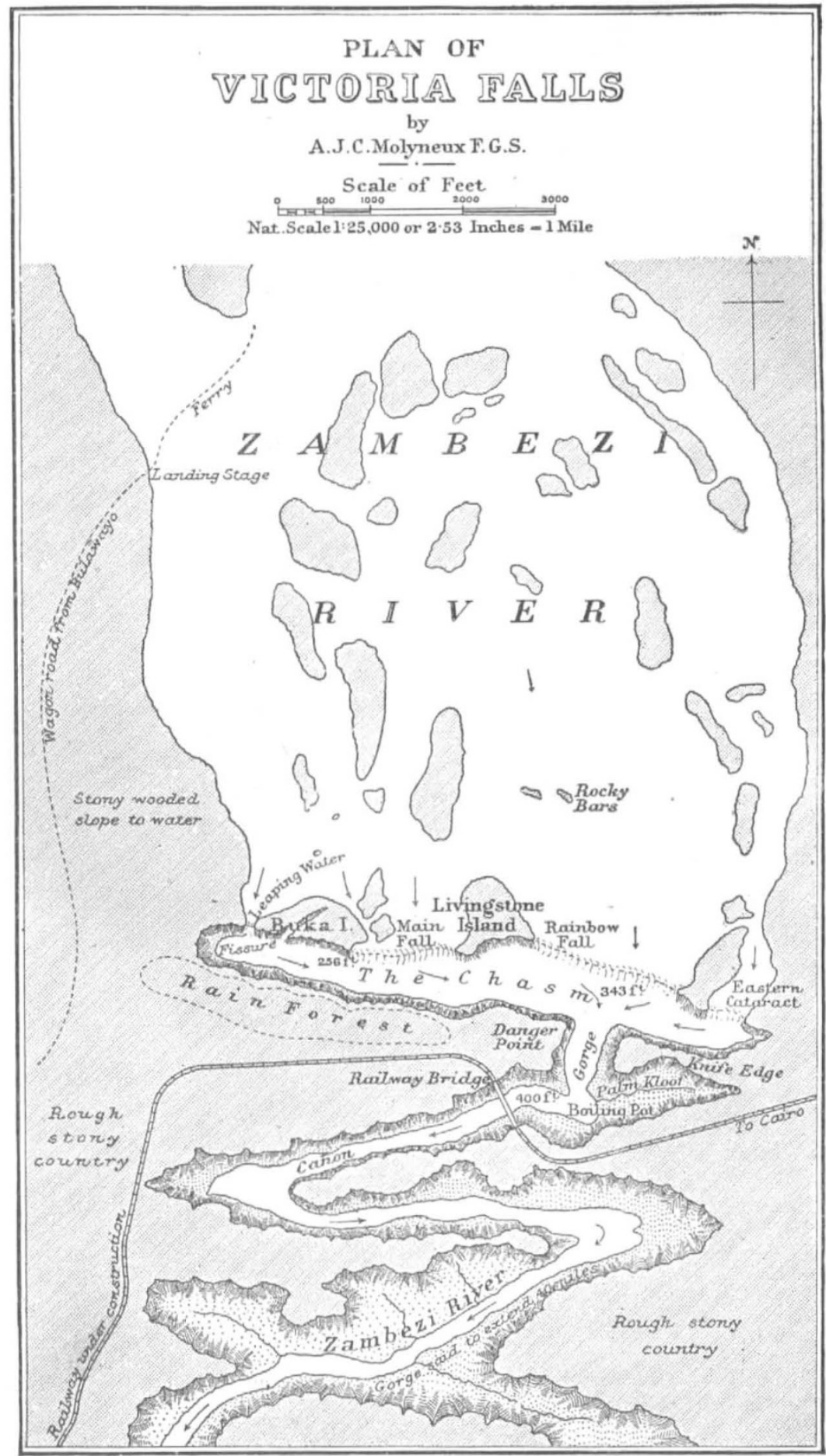

Fig. I. - Plan of Victoria Falls. From the Geographical Journal. author states that, as is common to all rocks of this nature, it is full of cracks and fissures due to contraction, generally assuming a columnar form. These columns can be seen at low water along the lip of the falls, more or 
less truncated as the verge is reached, and bearing little evidence of attrition (Fig. 2). Mr. Molyneux is of opinion that the cutting back of the falls is due to the perpetual hammering action of the vast bodies of water falling into, and down upon, the cracks between the basalt columns, assisted by the constant vibration of the rock from the precipitated masses of water, and that by this constantly exerted force the columns are rent asunder and fall into the chasm, taking with them huge and deep flakes of the precipice. At low water heaps of these blocks, as yet angular and unreduced, may be seen in the shallower ends of the chasm.

Such is one phase of the erosion of the falls. Another power is at work below the water line. The blocks that water, such parts as are protected by islands must be free from such erosion. To-day there are three important islands on the lip of the chasm, and more than fourteen large ones in 4 miles of river above the falls. In the channels between, there must be more prolonged submission to moving currents, by which the cataracts at the ends of the chasm are being deepened into sloping by-washes.

The falls have checked the deepening of the Upper Zambezi, and until they chisel the groove of the Grand Cañon back to the western edge of the basalt sheet, the upper reaches must continue to run at a high altitude and amid low-lying hills. This has prevented the Zambezi becoming a navigable river throughout, and has also had a marked influence on the geography of South Africa.

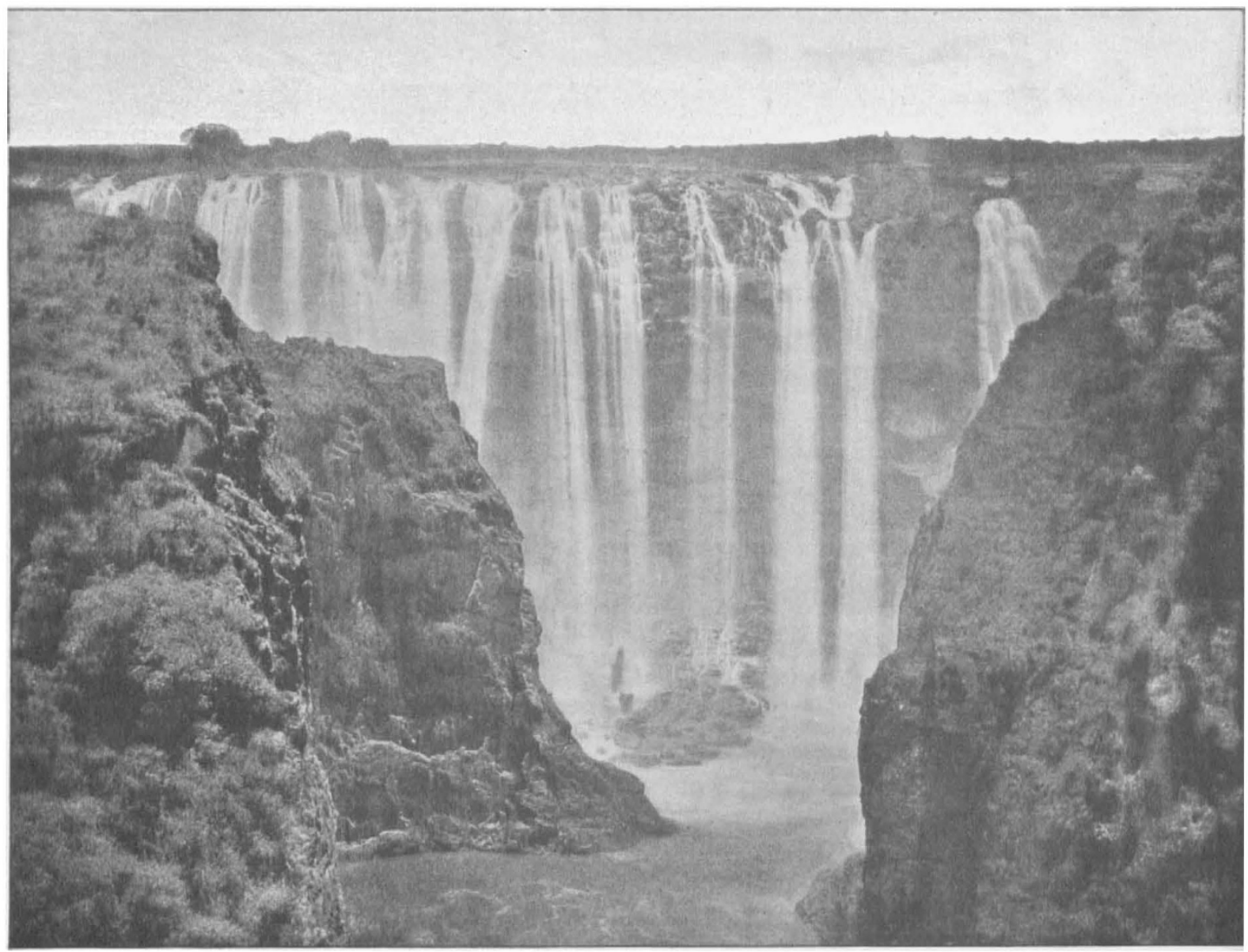

Proto. by Pedrotti, Bulawayo.

FIG. 2.-View of Victoria Falls seen through the jaws of the Gorge. Danger Point on the left; the promontory of the "knife edge" on the right. the Gorge. Danger Point on the
From the Geographical Jowrnal.

fall into the chasm disappear in the deeper waters at the jaws of the gorge-yet, impelled by the rush of the current in the confined walls, they must be grinding down and perpetually deepening the cañon, to emerge at the eastern end as rounded pebbles and form the shingle beds of the middle reaches.

The extraordinary zig-zags or acute angles in the cañon have always aroused comment, and the author thinks that two main causes are responsible for themthe position of islands that probably studded the river (as now) and also the existence of master joints and fissures in the basalt. On Boaruka Island this action is exemplified in a striking manner, for a stream can be seen falling down a crevice, that forms, peculiarly enough, another acute angle with the chasm.

Granted that the falls are due to the action of moving NO. 1852 , VOL. 7 I ]

\section{SEISMOLOGICAL NOTES.}

$T \mathrm{HE}$ attraction of the moon has always been felt by earthquake workers, whatever may be its effect on earthquakes themselves. The latest contributions to this aspect of seismology are two papers in No, 18 of the Publications of the Earthquake Investigation Committee in Japan. Prof. Omori deals with the lunar daily distribution, finding maxima of frequency between oh. and ${ }_{5} \mathrm{~h} .$, and again between $12 \mathrm{~h}$. and $13 \mathrm{~h}$., reckoning from the upper culmination. Dr. Imamura, dealing with the synodic monthly variation in frequency, finds that this shows an increase at the syzygies and quadratures; the former is attributed to the combined effects of the attraction of the sun and the moon, while the latter is explained by the fact that the time of high water at Tokio then coincides with that of the diurnal maximum of barometric 